\title{
Mispricing Persistence and the Effectiveness of Arbitrage Trading
}

\author{
Pascal Alphonse \\ Lille School of Management, University of Lille 2, France
}

This article examines whether mean reversion in stock index basis changes is actually induced by arbitrage trading, using intra-day arbitrage trade data. The empirical evidence suggests that arbitrage trading alone cannot account for all of the mean reversion in basis changes, even when infrequent trading is controlled for. This general mean reversion is consistent with mean reversion in liquidity and partial adjustment in the cash market. The behavior of arbitrageurs appears highly competitive. We find that on average the net arbitrage profit is at the competitive level of zero. Furthermore, it is suggested that some mispricing persistence may be related to time-varying liquidity. Accordingly, the results indicate that arbitrageurs pay attention to the depth of the market and value the early unwinding option (JEL: G13, G14).

Keywords: market microstructure, arbitrage trading, liquidity, stock index futures, market efficiency.

\section{Introduction}

The mean reversion in stock index futures basis changes is documented in a number of studies (see for example MacKinlay and Ramaswamy [1988] for the U.S., Yadav and Pope [1990], Yadav and Pope [1994] and Strickland and Xu [1993] for the U.K. and Lim [1992] for Japan). This mean reversion is traditionally viewed as a consequence of active arbitrage trading and appears as a by-product of efficient futures pricing. Recent papers on this topic make this analysis more precise and provide new indirect evidence-based on price data—of arbitrage

\footnotetext{
* I am indebted to Patrick Hazart and Dominique Martin from NYSE-Euronext for providing the data used in this study. I also thank Bruno Biais, Alain François-Heude, Larry Glosten, Nabil Khoury, Patrice Poncet, Chester Spatt, the editors as well as two anonymous referees for valuable comments and suggestions. The usual disclaimer applies.
}

(Multinational Finance Journal, 2007, vol. 11, no. 1/2, pp.123-156)

(C) Multinational Finance Society, a nonprofit corporation. All rights reserved. DOI: $10.17578 / 11-1 / 2-5$ 
effectiveness. For example, Yadav and Pope (1998) suggests that the mean-reversion characterizes changes in the basis when the futures price hit some trigger points only, due to transaction costs. Then, Yadav and Pope (1998) describes the behavior of the basis as a threshold autoregressive process. Following Kawaller (1991), Tse (2001) argues that transaction costs differ among arbitrageurs and suggests that the arbitrage sector should not be reduced to a representative arbitrageur. He shows that the observed mean reversion in mispricing changes is induced by heterogeneous arbitrageurs and shows that a smooth transition autoregressive process provides a better description of the mispricing behavior than the traditional threshold process. The same arguments are presented in Dwyer, Locke and Yu (1996). Likewise, Kempf (1998) examines the impact of short selling restriction and early unwinding opportunities on the dynamics of the mispricing.

Miller, Muthuswamy and Whaley (1994), however, challenges this traditional view of arbitrage trading and argues that infrequent trading in the stock market is a sufficient condition for the basis to exhibit some mean reversion. More recently, Theobald and Yallup (2001) argues that partial adjustment to new information leads to negative autocorrelations in basis innovation series. Lead-lag relationships between futures and spot prices constitutes a natural support for this partial adjustment. Finally, Neal (1996) shows that the traditional determinants of arbitrage trading (mispricing level and mispricing sign, time to expiration, early liquidation option) explain only a very low proportion of actual arbitrage trades. That is, arbitrage trading may not be as predictable as suggested in the works cited above. ${ }^{2}$ Thus, the prominent role attributed to arbitrage trading may in fact be driven by a misleading proxy for actual arbitrage trading and by indirect inference about arbitrage effectiveness. One way to cope with this difficulty is to base the results concerning the relationship between arbitrage trading and mean reversion in basis changes on actual arbitrage trades. This direct inference is the subject of this paper where the mean reversion in mispricing changes is examined using actual data on arbitrage trading on Euronext Exchange.

More precisely the paper makes two contributions to the existing literature on arbitrage trading and mispricing behavior.

2. To the best of our knowledge, the reasons explaining why arbitrage models behave so poorly are not well understood. Perhaps that the level of competition in the arbitrage sector, as modeled for example by Holden (1990), Lambrecht (2000) and in a more general setting by Spatt \& Sterbenz (1985), is underestimated. 
First, the results indicate that mispricing is not persistent because arbitrage opportunities are rapidly exploited by stock index arbitrageurs but also because of some general, non-arbitrage mean reversion in mispricing changes. This result is not evidence of some statistical illusion of the type defined by Miller, Muthuswamy and Whaley (1994) because we use quotes instead of transaction prices to compute the index. As a result the index value is not biased by some stale price effect induced by infrequent trading. ${ }^{3}$

It is suggested that this non-arbitrage mean reversion may be driven by (non-informational) liquidity shock, by partial quote adjustment in the cash market and by the lead-lag relationships between the futures and the stocks. The liquidity shock explanation is reminiscent to Kraus and Stoll (1972) who shows that large trades cause price reversals (reflected here in reversion in the basis) and is also consistent with the overbidding/undercutting strategies documented in Biais, Hillion and Spatt (1995).

The partial quote adjustment in the cash market may be induced by limit order traders that do not always respond to changes in fundamentals by instantaneously adjusting the quotes. This is consistent with observed stale quotes in the cash market and with the partial adjustment model of Theobald and Yallup (2001). Finally, according to the lead-lag explanation, it is possible that new information is impounded in one market first, say the futures market, causing an increase in the mispricing, and that stock market traders observing the futures price adjust their quotes, which decreases the value of the mispricing. ${ }^{4}$ Thus, one would naturally expect some mean reversion to take place without arbitrage trading.

The existence of non-arbitrage mean reversion in the basis changes departs from the recent results of Kempf (1998) or Tse (2001). This result may come from the fact that arbitrage trading is actually found to be far less frequent and predictable that it would be found by applying some mechanical trading rules. These data characteristics are not specific to our sample (see for example the description of the arbitrage data in Harris, Sofianos and Shapiro [1994]) and then must be related

3. It does not mean that all of the serial dependance is removed from the index series. It suggest that if the index series still exhibit some serial dependancy, then it must be related to information dissimination across the stocks and to price adjustments (e.g., Chan [1993]), not to cross sectional differences in trading frequency across the stocks.

4. See in a related context the analysis in Cheung and Fung (1997). 
to some determinants of arbitrage trading.

Second, the results indicate that the liquidity of the market, and especially the depth is a key determinant of arbitrage trading. To the best of our knowledge, this is the first time that the depth (in addition to the spread) is used as a determinant of arbitrage trading. Neal (1996) documents time variation is spread and suggests that it is related to arbitrage trading. Nevertheless, it should be the case that arbitrageurs are aware of the quantity of shares they can trade for a given price, the depth of the market. This is consistent with the arbitrage models of Kumar and Seppi (1994), Holden (1990, 1995) and Fremault (1991). It is also shown that in establishing an arbitrage position an arbitrageur takes into account the possibility to reverse rapidly the trade. We provide new evidence consistent with the early-liquidation option model of Brennan and Schwartz (1990). Finally, our results are consistent with what one would expect theoretically if arbitrageurs were $100 \%$ certain being able to unwind their position prior to the maturity date and competition among arbitrageurs had eliminated all excess rents. That is, we find that on average, the net arbitrage profit is at the competitive level of zero. Liquidity and time-variation in mispricing series may explain part of the dispersion observed in arbitrage trigger points.

The present paper is closely related to the papers due to Neal (1996) and Harris, Sofianos and Shapiro (1994) in that the three papers document and characterize a set of arbitrage orders. Nevertheless the analysis presented in this paper differs from these previous studies in several ways. First, a new and more recent dataset related to a screen-based, order-driven market in which the supply of liquidity relies on limit order traders only is used. The comparison with the U.S. case is interesting and may contribute to the debate on the ability of different trading systems to provide some heterogeneous classes of investors with liquidity (e.g., Venkataraman [2001]).

Second, the rules governing short sale constraints are also different in the U.S. and France. As shown in numerous papers, these rules affect the opportunity cost of funds (Kawaller [1991], Kempf [1998]), and then the arbitrage decision. In particular, we discuss the impact of the account settlement mechanism.

The size of the index is a third difference between the present study and the two others that use arbitrage data (Neal [1996] and Harris, Sofianos and Shapiro [1994]). The CAC 40 index is based on 40 stocks versus the 500 stocks of the S\&P. This difference may induce less infrequent trading, mimicking strategies and tracking errors so arbitrage 
in the French case may be less risky and the data more homogeneous than in the U.S. With respect to the size of the index, this paper is more related to Tse (2001), but using arbitrage data.

Fourth, as in Neal (1996) and Harris, Sofianos and Shapiro (1994), evidence of mean reversion induced by arbitrage trading is presented. However, the hypothesis that mean reversion in stock index basis changes is not induced by arbitrage trading only is also examined. This is a particularly important issue of this paper because, to the best of our knowledge, none of the papers that deals with this latter question (Kempf [1998], Tse [2001]) uses (arbitrage) trade data. As previously stated, this would be without consequences if arbitrage trading was a perfectly deterministic function of the mispricing, but it is not.

Fifth, the analysis of the determinants of arbitrage trading emphasizes the role of the liquidity, especially the depth of the market, and computes variables related to the arbitrage order imbalance and to the (expected) reversion in the basis in order to address the hypothesis of the early liquidation option.

The rest of the paper is organized as follows. The methodology is presented in section II. The data and the markets are described in section III. Section IV provides an analysis of the arbitrage order flow. Regression results are presented in section V. Section VI concludes.

\section{Research Methods}

The fair value of the futures is obtained by applying the traditional cost-of-carry model adapted for the specificities of the French stock market, the fixed-date settlement and the dividend tax credit systems. ${ }^{5}$ Mispricing is defined as in Mackinlay and Ramaswamy (1988) by the difference between the actual $\left(F_{t, T}\right)$ and theoretical prices $\left(F_{t, T}^{*}\right)$ of a futures with maturity $T$ priced at time $t$ and divided by the current index value $\left(S_{t}\right)$ :

$$
M I S_{t, T}=\frac{F_{t, T}-F_{t, T}^{*}}{S_{t}}
$$

Mispricing is also defined and measured with respect to deviations from

5. For an analysis of these features and their impacts on stock index futures valuation, see McDonald (2001) and Theobald and Yallup (1996). 
an arbitrage-free range defined from bid and ask quotes. Let $F_{A s k, t, T}^{*}$ and $F_{B i d, t, T}^{*}$ be the theoretical prices of a futures contract with maturity $T$ evaluated at time $t$ with the bid and ask stock quotes. The position of the actual price of a futures with maturity $T$ in this arbitrage-free range is measured at time $t$ by the variable $\theta_{t, T}$ defined as:

$$
\theta_{t, T}=\frac{F_{t . T}-F_{B i d, t, T}^{*}}{F_{A s k, t, T}^{*}-F_{B i d, t, T}^{*}}
$$

If the actual futures price is at time $t$ between the theoretical bid and ask values of the futures, then $0 \leq \theta_{t, T} \leq 1$, whereas long (cash and carry) arbitrages should be associated with $\theta_{t, T} \leq 1$ and short (reverse cash and carry arbitrages) with $\theta_{t, T} \leq 0$.

Nevertheless, we may note that, while the standard arbitrage condition implies that no arbitrage order should be submitted when the price of the futures stands in this price range, the presence of arbitrage orders within this range is consistent with arbitrageur valuing an option to unwinding their position before the maturity date. As stated by Brennan and Schwartz (1990), "it may be optimal to open a new arbitrage position even when the simple arbitrage profit is less than the cost of executing the simple arbitrage. The reason for this is that a simple arbitrage position carries with it an option to close out early and thereby make an additional arbitrage profit" ${ }^{6}$ The empirical analyses in Sofianos (1993) and Neal (1996) support this view for the U.S. markets.

Furthermore, one may expect all the arbitrage positions to happen in cluster at some unique trigger point less than $\theta_{t, T}=1$ for cash and carry arbitrage (and at some unique trigger point greater than $\theta_{t, T}=0$ for reverse cash and carry arbitrage) only if all the arbitrageurs value the unwinding option in the same way. On the contrary, difference in the valuation of the unwinding option should result in some dispersion of the arbitrage position inside the traditional "establish and hold to maturity" arbitrage trigger points $\left(\theta_{t, T}=1\right.$ and $\left.\theta_{t, T}=0\right)$. Differences in the valuation of the unwinding option may come from differences in position limits (Brennan and Schwartz [1990]), differences in transaction costs (Kawaller [1991] and Tse [2001]) or strategic behavior in an oligopolistic arbitrage sector (Lambrecht [2000]).

In order to assess the effective role of arbitrage trading in the mean

6. Brennan and Schwartz (1990), page 18. 
reverting process of the basis we have estimated the following Augmented Dickey-Fuller type regression : ${ }^{7}$

$$
\Delta M I S_{t}=\alpha+\beta T T M_{t}+\sum_{i=1}^{4} \gamma_{i} D_{i} M I S_{t-1}+\sum_{j=1}^{p} \phi_{i} \Delta M I S_{t-j}+\varepsilon_{t}
$$

where TTM denotes the time-to-maturity in days, MIS is the mispricing value and $\triangle M I S$ is the first difference in MIS. The time-to-maturity variable is included to account for the possibility of mean reversion around a time-dependent value.

The effective role of arbitrage trading is tested allowing for dummy variables $D_{t}$ in the regression. More specifically, if a long arbitrage position is established at time $t$ then $D_{1}=1$ and if a short arbitrage position is established then $D_{2}=1$. If there is no arbitrage trading at time $t$ then $D_{3}=1$ for positive mispricing and $D_{4}=1$ for negative mispricing. Hence at each time $t$ there is only one dummy that is equal to one and the other dummies are zero. We have also included $p$ lagged mispricing changes in the regression equation in order to correct for autocorrelation in mispricing changes.

Finally, a logit model is estimated in order to test for the significance variables that may be related to arbitrage trading models. First of all, the absolute value of the mispricing at time $t$ is retained as the main traditional determinant of arbitrage behavior (ABSMIS). As suggested by numerous papers, it may be the case that the required mispricing in establishing an arbitrage position is larger in case of reverse cash and carry than in cash and carry. The rule governing short sale constraints in France which are presented in the next section suggests that it would also be case in France. To test this hypothesis a dummy for negative mispricing (NEGMIS) is included. A positive relationship between arbitrage trading and these two variables is expected.

In order to take into account the influence of the persistence of mispricing on arbitrage trading, a time-stamped measurement of the duration of the mispricing (DURATION) is included in the model. The construction of this variable is explained below.

Data are sampled and the mispricings are indexed by their ranks in some sequences of successive positive, negative or zero mispricings.

7. See also Kempf (1998) for the use of the $A D F$ type regression in an analysis of the mispricing behavior. 
Thus, each mispricing is the $n_{t h}$ mispricing of a typical period of over-, under- or fair valuation of the futures. The duration of a mispricing at time $t$ is then defined as its rank at that time in a given mispricing period.

The hypothesis tested is that arbitrage trading is positively associated with this duration. The intuition is that it may take time for a mispricing value to become large enough to induce arbitrage trading. This delay may be caused for example by the conjunction of a fine price grid (a small tick size) and a price continuity rule between prices. Arbitrageurs may also look at mispricing persistence in order to gauge the probability of reversal in the basis (e.g., Chung [1991]) and thus the feasability of arbitrage.

The opportunity of establishing an arbitrage position may well be related to the liquidity of the market too. In fact, the amount of money earned in arbitrage trading should be related to the number of shares and contracts that may be traded in establishing the position. Therefore the depth of the market rather than the spread may be positively associated with arbitrage trading. This conjecture is test in considering simultaneously the bid-ask spread (SPREAD) and the depth (DEPTH) in the model. It may be noted that we use a directional measure of the depth in that we consider only the market side associated with the sign of the mispricing (depth at the ask for positive mispricing and depth at the bid for negative mispricing). A positive sign for DEPTH and a negative sign for SPREAD are expected.

Finally, and following Brennan and Schwartz (1990), we hypothesize that in establishing a new position, an arbitrageur is concerned with the option to liquidate the trade early. Investigations by Sofianos (1993) and Neal (1996) indicate that early liquidation is in fact the rule. To test for the presence of such an option value, three additional variables are considered: a forward-looking measure of reversal in the basis (REVERSAL), the time-to-maturity of the futures contract (TTM) and a measure of arbitrage order imbalance $(A O I M B)$.

The reversal variable is defined as the percentage of reverse mispricing over the next seven trading hours. ${ }^{8}$ For example if the current mispricing value is positive, then the variable is equal to the percentage of negative mispricing values observed over the next seven trading

8. There is no guideline for the choice of this duration. We chose seven trading hours because it is the duration of a trading day. Alternatives have been tested and showed that the results are not dependent on this particular choice. 
hours. This variable may be seen as the arbitrageurs' expectation about a future mispricing reversal. This variable is expected to be positively associated with arbitrage trading. The time to maturity of the contract is the number of days before expiration. It should capture at least some part of the time-varying component of the early liquidation option and is expected to be positively associated with arbitrage trading. The arbitrage order imbalance is measured by a dummy variable. The latter takes the value of 1 if the arbitrage that would be associated with the current mispricing value reduces the arbitrage order imbalance resulting from previous arbitrage trades, and 0 otherwise. The intuition is that arbitrageurs may be more favorable in establishing an arbitrage position if it reduces current arbitrage order imbalance, that is, if they liquidate their position early.

\section{The Market and the Data}

\section{A. The CAC 40 Cash and Futures Markets}

The analysis reported in this paper is related to the French stock and stock index futures markets. Until recently, the Paris stock exchange operated a system of account settlement, the Réglement Mensuel, or in English, the Monthly Settlement. ${ }^{9}$ Each year was divided up into twelve accounts. Accounts were of one-month duration, running from the fifth trading day preceding the last trading day of the month to the sixth trading day preceding the last trading day of the following month. Settlement of the trades during an account took place on the account day which is the last business day of the month following an account. Hence, normal settlement of trade took place between six days and one month and six days after a trade date.

The account settlement system has numerous implications for futures pricing (for a general treatment see Theobald and Yallup [1996]). One of them concerns short sales. Since all trades during an account are settled on the same account day, it gives arbitrageurs an incentive to open and close reverse arbitrage positions in the same

9. This situation has changed in September 2001 and all the trades are now settled on a day +3 basis. Brokers, however, offer investors the possibility to trade on the basis of the $\mathrm{SRD}$ (for Système de Règlement Différé) which is a device that mimics the functioning of the old monthly settlement. 
account. In that case, arbitrageurs sell the stocks short and buy them back later in the same account, with no need to pay a fee for borrowing the stocks. Nevertheless, when arbitrage positions are closed on the maturity of the futures, arbitrageurs in short position who buy stocks on that date will not receive the stocks until the relevant account day, that is about one month later. Thus, they have to borrow the stocks they sold short for a one- month period. Therefore, while the account settlement system facilitates short sales, it does not eliminate the borrowing cost of stocks for most of the reverse arbitrage positions. Furthermore, it introduces some uncertainty in the return of short arbitrage positions because the borrowing cost is not known at the time the reverse arbitrage positions are opened.

The futures market is a traditional open outcry market and the stock market is a screen-based, order-driven market. ${ }^{10}$ This electronic market operates without designated market makers so public limit orders are the only source of market liquidity. The five best bids and offers as well as their associated depths, except for the hidden limit orders, are continuously displayed to traders.

This transparency can affect the strategies of market participants. For example, limit order traders who are the most exposed to asymmetric information may protect themselves by cancelling their orders and leaving the market, leading to temporary market breakdowns or to high and uncertain transaction costs for arbitrageurs. In this context, the level of available liquidity may affect the timing of arbitrage trading and the persistence of mispricing. Furthermore, Biais, Hillion and Spatt(1995) indicate that most of the depth is concentrated on the best quotes.

\section{B. The Data}

Intra-day arbitrage trading data (which are not publicly available) have been obtained from EuroNext for the first quarter of 1995. While we had expected to access data related to a more recent period, the data set we obtained and worked on allows us to look at the actual trading behavior of arbitrageurs, not their supposed behavior implied by the cost of carry model, and then deserves further analysis.

These data indicate the time of the arbitrage order initiation, the side

10. This situation changed in spring 1998 and the stock index futures market is now an electronic market managed by the Liffe. 
of the market (cash and carry arbitrage versus reverse cash and carry arbitrage), the number of different stocks in each arbitrage order and the money value of each arbitrage order. ${ }^{11}$

A first characterization of these data is provided in section III. We use time stamped transaction prices for the CAC 40 futures and intraday stock quotes for the period from January 3rd, 1995 to March 31st, 1995 to compute the theoretical fair value of the futures. The intra-day data are extracted from the Historical Market Database of EuroNext. The interest rates used to evaluate the cost-of-carry of the futures are the French one day lending rate and several PIBOR with maturity ranging from one to three months. These rates are from Thomson Financial. The daily number of shares issued by each firm and the dividend data are extracted from the Historical Market Database of EuroNext.

In order to avoid measurement errors due to the stale price effect induced by infrequent trading, we do not use the index value computed and displayed each 30 seconds by Euronext because it is based on the last recorded transaction prices. ${ }^{12}$ Instead, an index value based on mid-quote points is computed and sampled on a 30-second interval grid. This choice is not just cosmetic because it has been suggested that the mean reversion that traditionally characterizes the mispricing series may be due to a stale price effect related to the index construction rather than arbitrage trading (Miller, Muthuswamy and Whaley [1994]).

There are some advantages using a quote-based index versus a trade-based index. First, a quote-based index should reflect the true value of the stocks more accurately than a trade-based index because quotes adjust more frequently than prices (see for the French case the analysis in Biais, Hillion and Spatt [1995]). Second, quotes reflect the true cost of liquidity and indicate the price at which stocks can be traded. This allows us to take into account the possibility of time variation in the cost of liquidity. Third, a quote-based index is by definition not affected by infrequent trading.

Despite these advantages, there are still some drawbacks using quotes versus prices. In short, a quote-based index is essentially a "virtual" index. In particular, there is no reason for the (true) stock value

11. It also appears that the number of active arbitrageurs is limited. Inspection of the arbitrageur data ID shows that about $90 \%$ of the orders are submitted by only 15 arbitrageurs and the first three of them submit slightly more than one third of the total number of orders.

12. Stale price effects and index autocorrelation should appear as soon as the stocks have different trading frequency. 
to be half way between the bid and ask quotes. This assumption introduces noise in the measurement of the value of the stocks. Further, market makers adjust their quotes when they up-trade their beliefs about the value of the asset they trade in, but they also adjust their quotes in order to manage their inventory. Therefore, one may observe variations in a quote-based index although no information arrival motivates such variations. Again, this phenomenon introduces noise in the measurement of the value of the stocks. Finally, quotes may not adjust immediately to new information. This partial quote adjustment should create some stale-quote effects and finally autocorrelation in the index price changes series. Thus, deciding which of the index metrics is the best appears very difficult because each metrics has its advantages and its drawbacks. In this paper, we follow the analysis of Froot and Perold (1995) and use a quote-based index.

Two other indexes are computed in the same way with all the available bid and ask quotes in order to compute the value of the variable $\theta_{t, T}$.

Finally, data referring to the first and last five minutes of trading as well as overnight measures are ignored because of the opening and closing specific procedures and behaviors. Data concerning expiration days are also discarded.

\section{The Arbitrage Trading Activity}

The main results of this paper are based on intra-day arbitrage data provided to us by Euronext. Arbitrage orders are extracted by the exchange from its historical trading database. This database appears much richer than the files marketed by the exchange. In particular it allows the exchange to track some particular type of orders and trades, especially index arbitrage orders and trades. Nevertheless, the exchange is essentially concerned by the evolution of general statistics concerning arbitrage trading (e.g., the net open interest related to arbitrage trading). By contrast, our research concerns the intra-day behavior of index arbitrageur.

For the three months considered in this study, and after the elimination of the opening, closing and expiration-day data, 1,880 arbitrage orders were retained. The number of sell orders is slightly larger than the number of buy orders and accounts for about $56 \%$ of the sample. Under the assumption of a uniform distribution of these orders 
over time, this corresponds to an average of 29 arbitrage orders per day. The average number of different stocks by basket order is 39.3. It suggests that arbitrageurs do not enter into index tracking strategy with a reduced number of stocks. The average size of an order is equal to 13.96 millions of French francs, which is equivalent for an index level of 2000 points to 35 futures contracts.

Time series with the recorded program trades expressed in units of ten millions of French francs as a variable are set up. The length of each interval of time is fixed at 30 seconds, that is, orders are aggregated with respect to this time scale. When no arbitrage order occurs then the variable takes the value of zero. The independence of the submissions is then characterized by the distribution of orders per interval and by a transition matrix. The distribution of orders is presented in table 1.

The first row in table 1 shows the frequency distribution of 30 -second intervals conditional on the number of arbitrage order submitted in just one 30-second interval and is expressed as a percentage of the total number of intervals. It appears that arbitrageurs trade very infrequently. The number of 30 -second intervals concerned with arbitrage orders represents less than $2 \%$ of the total number of periods. Furthermore, arbitrage order submissions appear to be highly concentrated. The second row of the table shows the frequency distribution of arbitrage orders. In one third of the cases, there are more than one order submission per period of 30 seconds. This clustering effect is reinforced by the autocorrelation of the order submission as suggested by the conditional probabilities of the transition matrix presented in table 2.

The conditional probability that a buy (sell) order follows another buy (sell) order appears significantly greater than the unconditional probability of a buy(sell) order occurrence. This phenomenon indicates that basket orders of a same side of the market arrive in clusters. This evidence is consistent with the related findings of Harris, Sofianos and Shapiro (1994) for the U.S. market. It suggests that more than one order is needed to induce mean revertion in basis changes but also that arbitrageurs react roughly simultaneously in some "jumping the gun" competition, as analyzed for example by Spatt and Sterbenz (1985). Nevertheless, results of Biais, Hillion and Spatt (1995) suggest that this order flow autocorrelation does not characterize the arbitrage order flow specifically.

One can expect that on average the cash and carry arbitrage (associated with buy basket orders) is related to a positive mispricing 


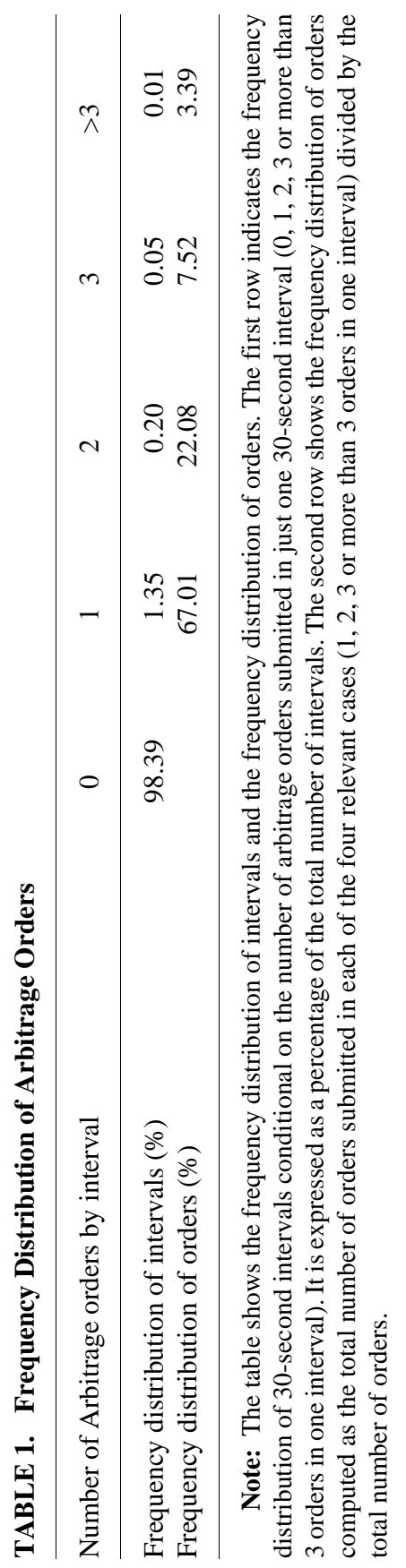


Mispricing Persistence \& Arbitrage Trading

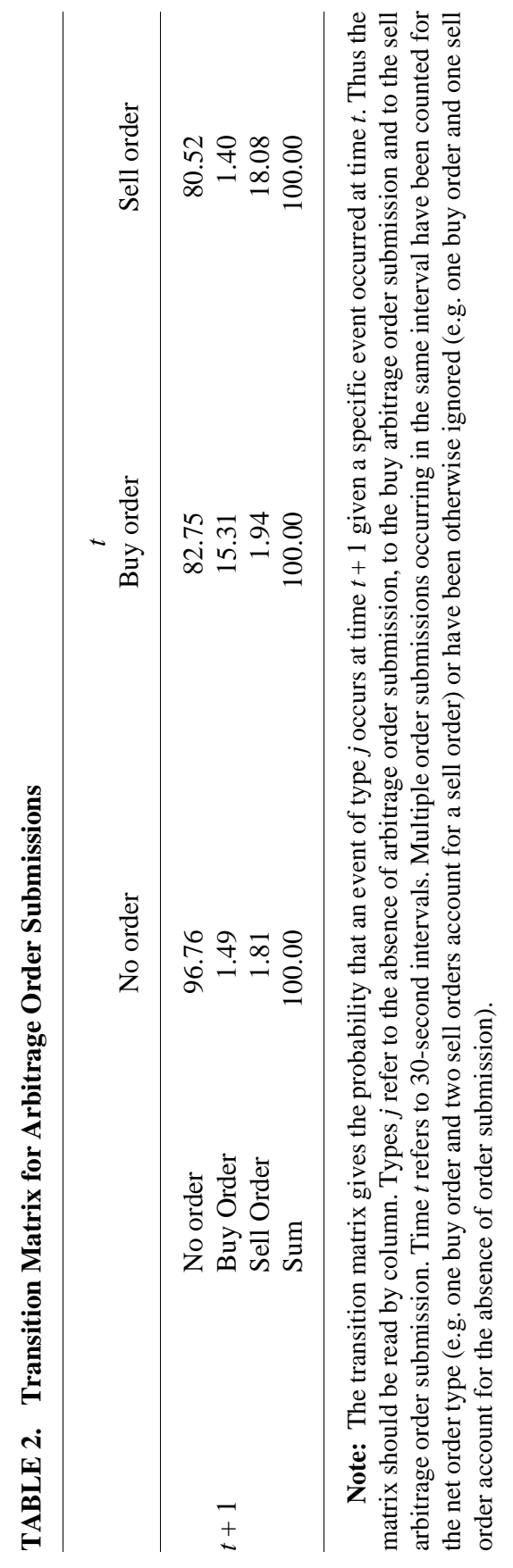




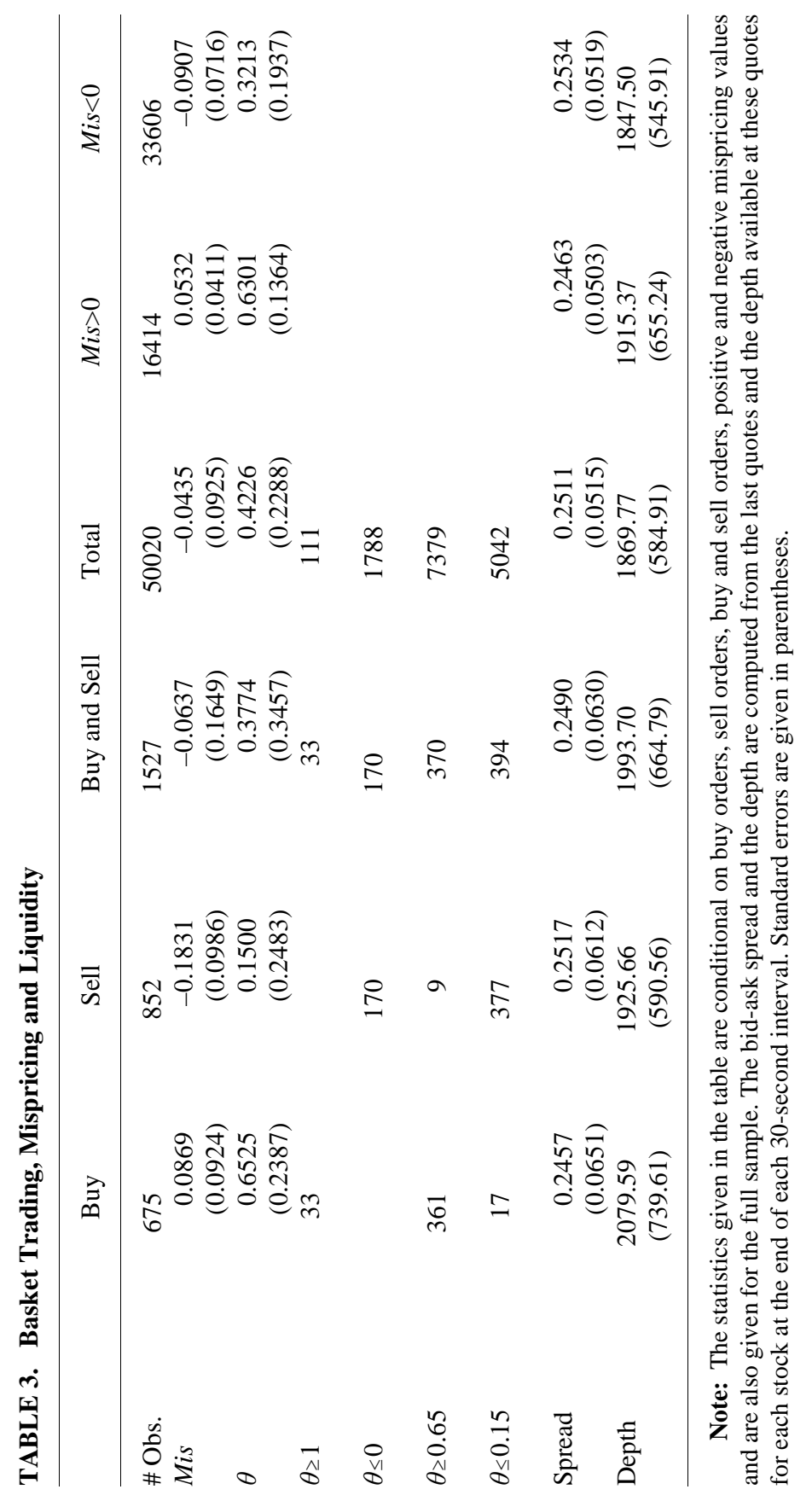


value and that on average the reverse arbitrage (associated with sell basket orders) are related to a negative mispricing value. The results presented in table 3 show that it is actually the case.

The first row of table 3 gives the number of events considered. As a result of the clustering effect noted above, the number of arbitrage events that appears here is slightly lower than previously stated because orders are aggregated with respect to 30 -second intervals. Over the sample period the futures more often appears underpriced (67.2 percent of the time) than overpriced which is consistent with the asymmetry observed between the number of cash and carry and reverse cash and carry trades.

The average mispricing value is reported in the second row of the table conditional on a cash and carry event, a reverse cash and carry event, an arbitrage trading event and for the full sample. The average values for the positive and negative mispricings are also provided. It appears that on average cash and carry (reverse cash and carry) arbitrages are associated with a positive (negative) value of the mispricing, which is consistent with the traditional cost of carry argument.

Nevertheless these average bounds are not symmetrically distributed around the theoretical futures value. The absolute value of the average mispricing for reverse cash and carry arbitrages is about twice as large as the value of the average mispricing for cash and carry trades. This asymmetry also appears in the average value of the mispricing computed for the full sample and indicates that the value of the futures computed from the cost of carry formula may be systematically too large. Therefore it may be the case that the asymmetry observed in the arbitrage bound just reflects the undervaluation of the futures relative to the theoretical price we computed. Finally it appears that the discount relative to the cost of carry price is small with an average value of 0.043 percent of the index where the average bid-ask spread on a portfolio that duplicates the index equals 0.25 percent of the index over the period.

The average value of $\theta$ is displayed in the third row of the table. The mean value computed from the total sample (0.4226) indicates that the actual futures value is lower than the average value of the theoretical futures computed with the bid and ask stock quotes and confirms the previous finding. More importantly, the mean value of the variable $\theta$ associated with cash and carry (say $\theta_{b u y}$ ) or reverse cash and carry (say $\theta_{\text {sell }}$ ) arbitrages suggests that the size of the mispricing that triggers arbitrage is significantly reduced vis-à-vis the size of the mispricing 


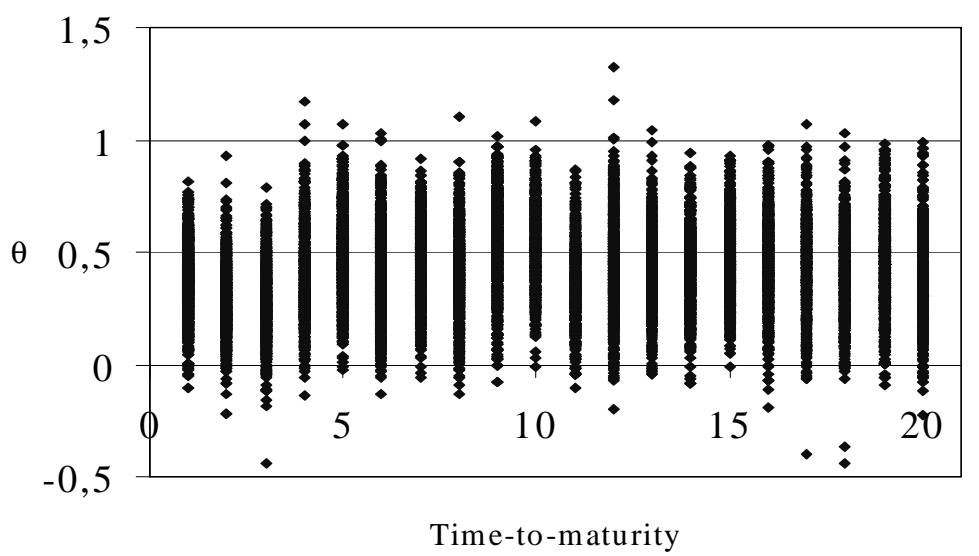

FIGURE 1.-Theta against Time-to-Maturity — January 1995 Contract This figure displays the variable theta against time-to-maturity for the January 1995 contract. Observations on the same day form vertical lines and days are counted to maturity.

associated with "simple arbitrage opportunity" (Brennan and Schwartz [1990]), that is mispricing associated with arbitrage position held until maturity. The reported means are 0.6525 and 0.1500 for $\theta_{b u y}$ and $\theta_{\text {sell }}$, respectively. Corresponding "simple arbitrage opportunity" bounds would have been 1 and 0 for $\theta_{b u y}$ and $\theta_{\text {sell }}$, respectively.

This finding is consistent with the early liquidation option model of Brennan and Schwartz (1990) — establishing an arbitrage position can be viewed as making the arbitrage and simultaneously acquiring an option to unwind the position when there are arbitrage profits from unwinding it - and is in accordance with previous empirical evidence provided by Sofianos (1993) and Neal (1996) for the U.S. market. ${ }^{13}$

Finally, we note that $\theta_{b u y}-\theta_{\text {sell }}=0.5$, which is exactly what one could expect theoretically if arbitrageur were $100 \%$ certain of being able to unwind their position prior to the maturity date and competition among arbitrageur had eliminated all excess rents. That is, if the gross profit is half the spread when establishing a position plus half the spread

13. Unfortunately we cannot provide statistics based on a distinction between the establishing and liquidating trades because our database provides no information on such a distinction. Nevertheless in the next section we test for the influence of variables that may be related to the early liquidation option model. 


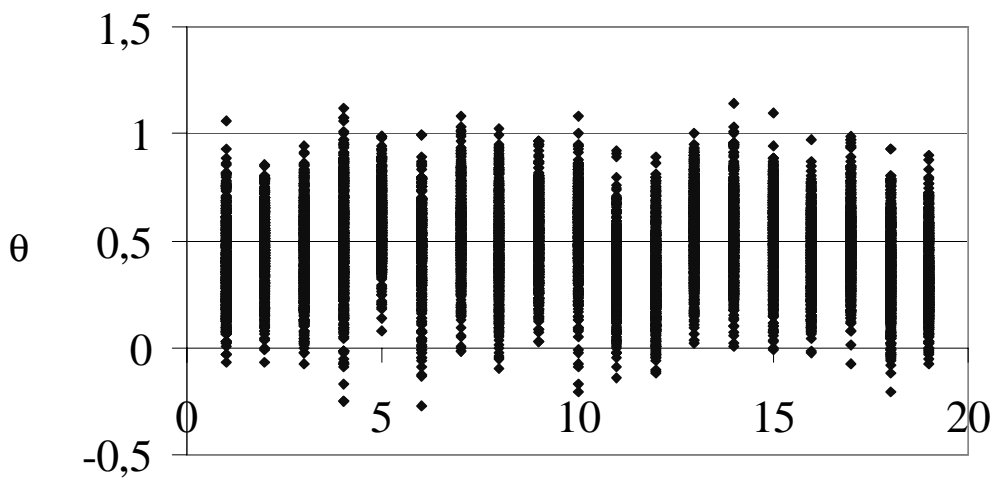

Time-to-maturity

FIGURE 2.- Theta against Time-to-Maturity - February 1995 Contract This figure displays the variable theta against time-to-maturity for February 1995 contract. Observations on the same day form vertical lines and days are counted to maturity.

when unwinding the position (with certainty), then the net arbitrage profit is at the competitive-level of zero. ${ }^{14}$

In this context, it would be interesting to gauge how frequently and consistently one is able to unwind a position early. With this in mind, we made simple plots of the evolution of $\theta$ against time-to-maturity for each of the 3 contracts maturing during our sample period. These plots are very similar to the plots A1-A16 in Brennan and Schwartz (1990) and are presented in figures 1 to 3 . Observations on the same day form vertical lines and days are counted down to maturity.

As discussed in Brennan and Schwartz (1980), maximum arbitrage profit are realized when $\theta$ passes from one extremum to another. Assuming that no arbitrage is possible inside a band equal to one half of the spread, it seems that the intra-day evolution of $\theta$ makes it possible for arbitrageur to trade in cash and carry and in reverse cash and carry each day, and that for the most part of the days of the sample. Therefore it may be the case that arbitrageurs can enter into new positions or close existing ones almost each day, trading mainly on a daily basis. However, the 2-dimensional view of these plots may be misleading,

14. We thanks an anonymous referee for pointing out this fact. 


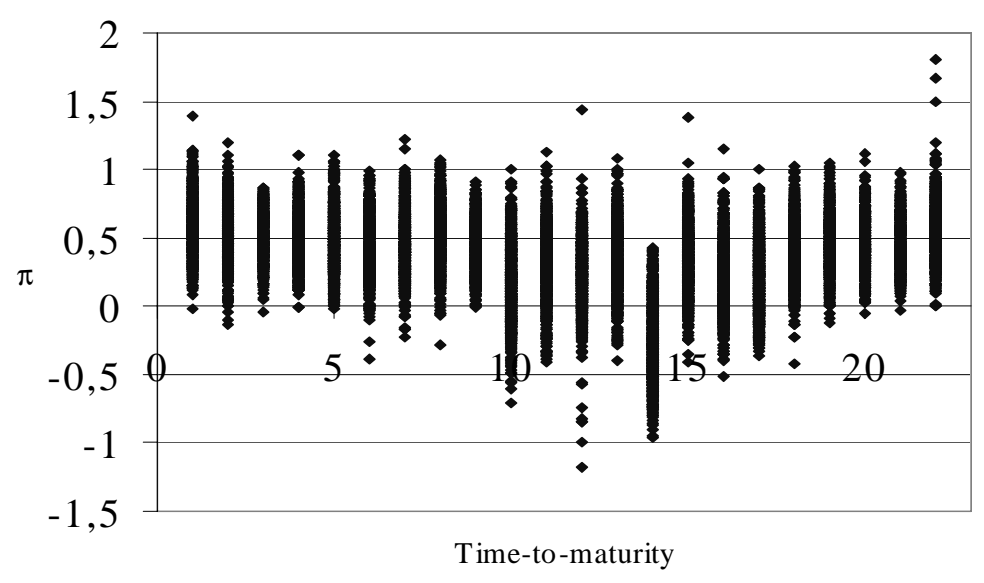

FIGURE 3.- Theta against Time-to-Maturity - March 1995 Contract This figure displays the variable theta against time-to-maturity for the March 1995 contract. Observations on the same day form vertical lines and days are counted to maturity.

making us to overestimate the weight of larger and smaller observations. Figure 4 presents a simple histogram of the observations against time-to-maturity and shows that the observations are indeed much less dispersed. This figure also suggests possible time-variation in the mean value of $\theta$. The analysis of some possible trigger points deserve further comments.

Consider first the trigger points associated with the "establish and hold to maturity" arbitrage. The number of arbitrage orders submitted when the mispricing exceeds the bounds $\theta=1$ or $\theta=0$ appears limited, about 13.3 percent of all arbitrage trades as shown in rows 4 and 5 of table 3. In other words, arbitrageurs expect most of the time to unwind their position before maturity and price the futures accordingly. However, if the futures becomes too cheap/expensive vis-à-vis the stocks, then they trade heavily. For example, while the futures appears overpriced less than 1 hour over the 3 month covered in the study (111 observations of 30 -second intervals, that is 0.22 percent of the calendar time analyzed), it concentrates during that 1-hour period more than 2 percent of the arbitrage orders. One should also note that the number of violations is also limited, representing less than 3.8 percent of the 


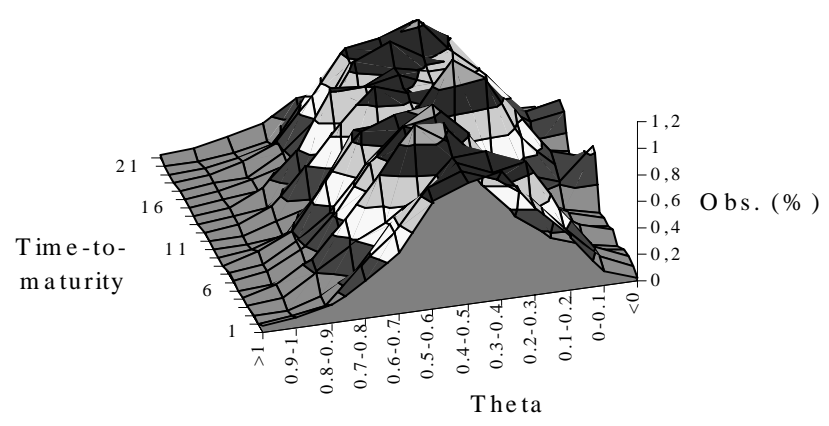

FIGURE 4.- Mispricing Distribution

This figure displays the distribution of mispricing against time-to-maturity for the period from January 1995 through March 1995. Data are aggregated by increments of theta of 0.1 .

number of intervals, this percentage being probably overestimated due to the small undervaluation of the futures we discussed previously. All in all, this suggests that on average the futures is well priced, but also that arbitrage trading will be difficult to predict with the traditional cost of carry argument alone.

Consider now the trigger points associated with competitive arbitrageurs trading in anticipation of (nearly always) unwinding early. These are obtained by adding and subtracting on-quarter of the spread to the average mispricing which is about $\theta=0.4$, yielding to triggers points $\theta_{b u y}$ and $\theta_{\text {sell }}$ equal to 0.65 and 0.15 , respectively. Note that these trigger points are exactly what we see on average, i.e. the mean value reported in the third row of the table and discussed previously. The number of buy(sell) arbitrage orders above(below) these points are reported in table 3, raws 6 and 7. As expected, a large proportion of arbitrage orders are submitted at and above the value $\theta_{b u y}=0.65$ and at and below $\theta_{\text {sell }}=0.15$. The reported evidence indicates that 50 percent of the arbitrage orders are concentrated on 25 percent of the trading time. However, this also means that about 50 percent of arbitrage trading is still not well explained. Figures 5 and 6 provide a more precise picture of when arbitrage positions are established. Each 


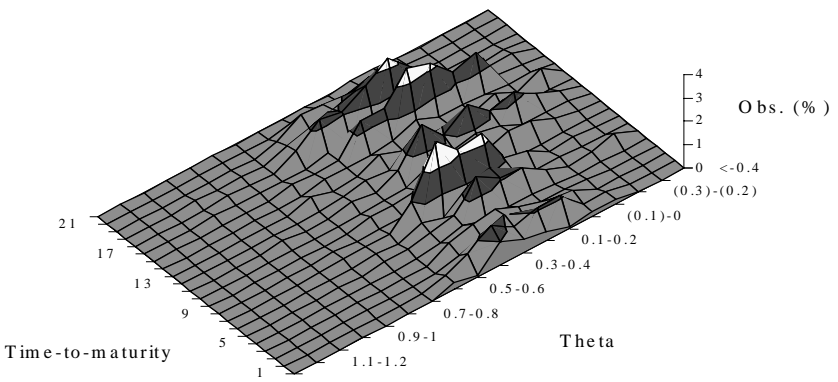

FIGURE 5.- Cash and Carry Arbitrage Distribution

This figure displays the distribution of cash and carry arbitrage against time-to-maturity for the period from January 1995 through March 1995. Arbitrage data are aggregated by increments of theta of 0.1 .

histogram reports the repartition of the arbitrage trades by 0.1 increments of $\theta$.

These figures confirm that there is still a lot of dispersion around the triggers points $\theta_{b u y}=0.65$ and $\theta_{\text {sell }}=0.15$. Furthermore, they show that there is some time-variation in the trigger points. One possible reason for these behaviors may be found in an argument initially developed by Kawaller (1991). She argues that "no single break-even price is universally appropriate, but rather that the break-even price for a given institution depends on the motivation of that firm as well as on its marginal funding and investing yield alternatives"(Kawaller [1991, p. 453]). The threshold models developed by Tse (2001), Yadav and Pope (2000) and Dwyer, Locke and Yu (1996) are built on the same hypothesis of heterogeneous arbitrage.

The bid-ask spread associated with buy and sell orders is not significantly different from its full sample mean ( $t$-stat for the difference equals -1.2437). Accordingly, it suggests that there is no systematic pattern in the arbitrage bounds associated with arbitrage orders that would be related to variations in the bid-ask spread. Put another way, it means that arbitrage trading is not related to large mispricing values induced by some liquidity shocks affecting the bid-ask spread in the stock market.

Nevertheless, the data indicate that a liquidity pattern is found in the 


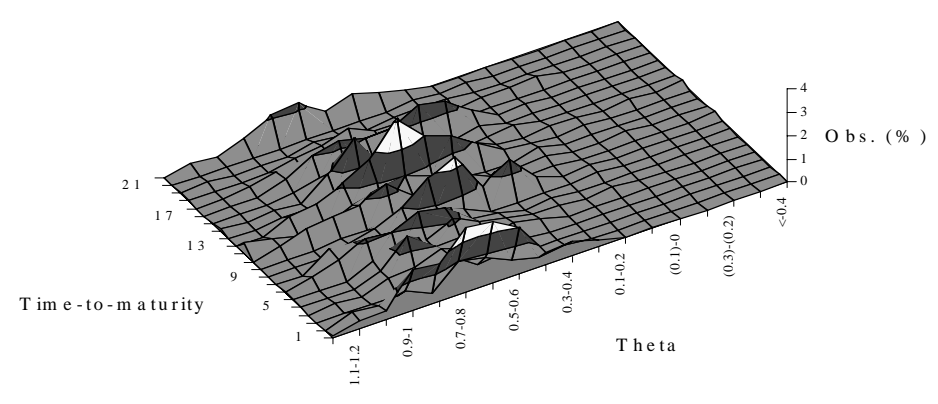

FIGURE 6. - Reverse Cash and Carry Arbitrage Distribution This figure displays the distribution of reverse cash and carry arbitrage against and time-to-maturity for the period from January 1995 through March 1995. Arbitrage data are aggregated by increments of theta of 0.1 .

number of shares available at the best quotes (i.e., the depth). At the time of arbitrage trading the depth at the best quotes appears significantly larger than the average depth ( $t$-stat for the difference equals 7.20). This suggests that the submission of arbitrage orders may sometimes be constrained by a lack of liquidity in the market. Furthermore, it suggests that some mispricing persistence may be induced by this lack of liquidity.

In order to illustrate this point further, we computed the average depth over the sub-sample where all mispricing values inside some transaction bounds were discarded and compared it to the average depth corresponding to arbitrage orders submitted in this sub-sample of data. Taking for example the average mispricing values associated with buy and sell orders as some (arbitrary) transaction bounds, we find that the average depth over the sub-sample is equal to 1880.89 shares where the average depth associated with buy and sell orders over the sub-sample equals 1983.66 shares with a $t$-stat for the difference of 4.10 and highly significant. $^{15}$

15. The same computation for the spread gives the value of 0.273 percent and 0.268 percent for the sub- sample and for the orders over this sub-sample, respectively, with a $t$-stat for the difference of 2.01 . 


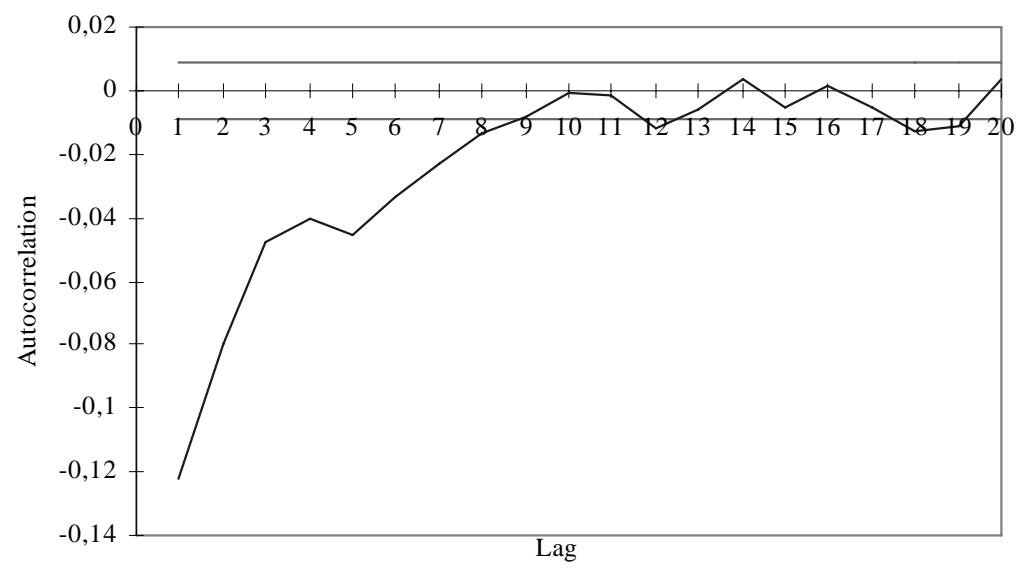

FiguRE 7. - Basis Changes Autocorrelation Function

This figure displays the autocorrelation function of the CAC40 basis changes for the period from January 1995 through March 1995. Data are sampled on 30-second intervals. Confidence intervals of $+/-2$ standard deviations (Bartlett formula) are also reported to test the null hypothesis of zero autocorrelation.

This is consistent with the view that arbitrage is not undertaken when the supply of liquidity appears too low, even when the mispricing value exceeds some thresholds. We present a test of this hypothesis in the next section.

\section{Regression Results}

Before we turn to the estimates of the regressions, we consider the autocorrelation function of the mispricing changes series. This autocorrelation function is of interest because first and higher orders of autocorrelation coefficients show the persistence of mispricing (e.g., Mackinlay and Ramaswamy [1988]). The estimated autocorrrelation function is presented in figure 7 .

We note that the mispricing changes series exhibit significant negative autocorrelation which is in accordance with the mean reverting behavior one could expect for the basis. We also observe that the value 
of the autocorrelation coefficients drops significantly after the first lag and becomes insignificant after eight lags, that is after four minutes. Indeed, this latter observation suggests that mispricing is not persistent. Table 4 presents the estimation of the impact of arbitrage trading on mean reversion. ${ }^{16}$

The coefficients on $D_{1}$ and $D_{2}$ are statistically significantly different from zero. This result shows that mean reversion in basis changes is at least in part induced by arbitrage trading. The estimated coefficients on $D_{3}$ and $D_{4}$ are also significantly different from zero. This finding suggests that some general mean reversion exists even in the absence of arbitrage trading. However, we should also note that in terms of magnitude, the coefficients on $D_{1}$ and $D_{2}$ are much larger than the coefficients on $D_{3}$ and $D_{4}$. In other words, arbitrage trading explains far more of the mean reversion than other non-arbitrage forces.

Where does this mean reversion come from? The statistical illusion hypothesis (Miller, Muthuswamy and Whaley [1994]) is not relevant here because we use a mid-quote index to compute the basis and therefore eliminate the stale price effect associated with transaction price. We next consider other possible explanations for non-arbitrage mean reversion.

One hypothesis is related to time-variation in the supply of liquidity in the stock market. Suppose for example that the ask price increases as a consequence of a non-informational liquidity shock. In that case the basis, whether it is computed with the transaction prices or the mid-quote points drops and a mispricing appears. Nevertheless no arbitrage will take place because neither the bid quotes for the stocks, nor the quotes of the futures have changed. At the same time, limit order traders may undercut on the large ask quotes to gain time-priority and thus provide liquidity at a better price. In doing this they force the mid-quote price to come back to its equilibrium (pre-trade) level and then they eliminate the mispricing. In that case, the mispricing should exhibit a mean reversion pattern without arbitrage trading. Evidence of limit order traders over-bidding/undercutting on large spreads and the low level of depth out of the best quotes (e.g., Biais, Hillion and Spatt [1995]) is consistent with this explanation.

16. In order to correct for autocorrelation in mispricing changes, 29 lagged mispricing changes are used. As a consequence, and in order to avoid inter-day effects when estimating mean-reversion coefficients, the first 30 observations of each day are discarded. The total sample reduces to 48,190 . 
TABLE 4. Mean Reversion and Arbitrage Trading

\begin{tabular}{lcccccc}
\hline & $\alpha$ & $T T M$ & $D_{1}$ & $D_{2}$ & $D_{3}$ & $D_{4}$ \\
\hline $\begin{array}{l}\text { Coefficient } \\
t \text {-stat }\end{array}$ & $\begin{array}{c}0.0008 \\
(1.87)\end{array}$ & $\begin{array}{c}-0.0001 \\
(-2.11)\end{array}$ & $\begin{array}{c}-0.2754 \\
(-22.14)\end{array}$ & $\begin{array}{c}-0.1412 \\
(-21.95)\end{array}$ & $\begin{array}{c}-0.0761 \\
(-12.17)\end{array}$ & $\begin{array}{r}-0.0163 \\
(-5.5986)\end{array}$ \\
& \# Obs. $=48160$ & & $R^{2}=0.0865$ & \multicolumn{2}{c}{$Q(36)=42.3443$} \\
\hline
\end{tabular}

Note: This table contains the results of the mean reversion equation for the mispricing:

$$
\Delta M I S_{t}=\alpha+\beta T T M_{t}+\sum_{i=1}^{4} \gamma_{i} D_{i} M I S_{t-1}+\sum_{j=1}^{p} \phi_{i} \Delta M I S_{t-j}+\varepsilon_{t}
$$

where TTM denotes the time-to-maturity in days, MIS is the value of the mispricing and $\triangle M I S$ is the first difference in MIS. If a long arbitrage position is established at time $t$ then $D_{1}=1$ and if a short arbitrage position is established then $D_{2}=1$. If there is no arbitrage trading at time $t$ then $D_{3}=1$ for positive mispricing and $D_{4}=1$ for negative mispricing. Whenever the dummies are not equal to 1 , they are zero.

Thus, it may be the case that this liquidity effect results in a bid-ask bounce effect which in turn produces a moving average component in the index dynamics (e.g., Stoll and Whaley [1990]). ${ }^{17}$ Then, following Miller, Muthuswamy and Whaley (1994), we conjecture that the liquidity effect induces at least some part of the negative autocorrelation in mispricing changes. Finally, the observed mean reversion due to a liquidity shock must be economically small and the results support that.

An alternative explanation for non-arbitrage mean reversion relies on the lead-lag relationships between the futures and the stocks. ${ }^{18}$ It is possible that new information is impounded in one market first (say stock index futures), causing an increase in mispricing, and then traders observe the change in futures price, and make corresponding changes in limit order (by canceling and resubmitting at new limit order prices) in the underlying stocks, which decreases mispricing. Thus, one would naturally expect some mean reversion to take place without arbitrage trading. Evidence of stale quotes, not prices, in the cash market is consistent with this hypothesis. The first order autocorrelation for the mid-quote index return series is 0.184 and is significantly different from zero.

17. Additional results available upon request indicate that the index return dynamics is best modeled as an $\operatorname{ARMA}(2,1)$.

18. We thanks an anonymous referee for pointing out this explanation. 
Finally, one can also consider the partial adjustment model of Theobald and Yallup (2001) and the information dissemination model of Chan (1993) as possible candidates. These models propose rationales for stale prices and index autocorrelation that differ from the infrequent trading hypothesis.

The results concerning the determinants of arbitrage trading are presented in table $5 .{ }^{19}$

The results indicate that the probability for an arbitrageur to trade is positively associated with the size of the price discrepancy but also that this size effect is more pronounced for negative mispricing. This result is in accordance with the descriptive statistics presented above and with numerous papers that indicate that arbitrage bounds are not symmetrically distributed around the theoretical futures price. This is consistent with the cost and uncertainty that characterize short sales in reverse arbitrage.

As suggested previously the results show that arbitrageurs take into account the depth of the market when establishing a position. Furthermore, it seems that arbitrageurs also focus on the bid-ask spread. This latter result is probably induced by the larger mispricings for which the size of the spread matters.

The negative and significant coefficient for the DURATION variable is puzzling because our hypothesis was that the longer the futures stayed over-priced or under-priced, the higher would be the probability for an arbitrageur to establish a position. This is in fact not the case, perhaps because the futures may stay over-priced or under-priced for a long period of time but at a level that makes arbitrage unattractive. We may also consider that arbitrage trading reduces large mispricings but does not eliminate them instantaneously. In order to take into account these possibilities we re-estimated the model with the DURATION variable defined over various threshold but the estimated coefficient of the variable DURATION was still negative and significant. We also plotted the average value of the cumulative changes in the mispricing value from 10 minutes before the trade to 10 minutes after the trade. The resulting pattern for cash and carry and reverse cash and carry arbitrages is presented in figure 8 .

Inspection of the figure indicates that on average mispricing rises

19. It is not clear whether the explanatory variables should be measured at time $t$ or at time $t-1$. Fortunately the results are not affected by this choice and we decided to report the results based on variables measured at time $t$. 


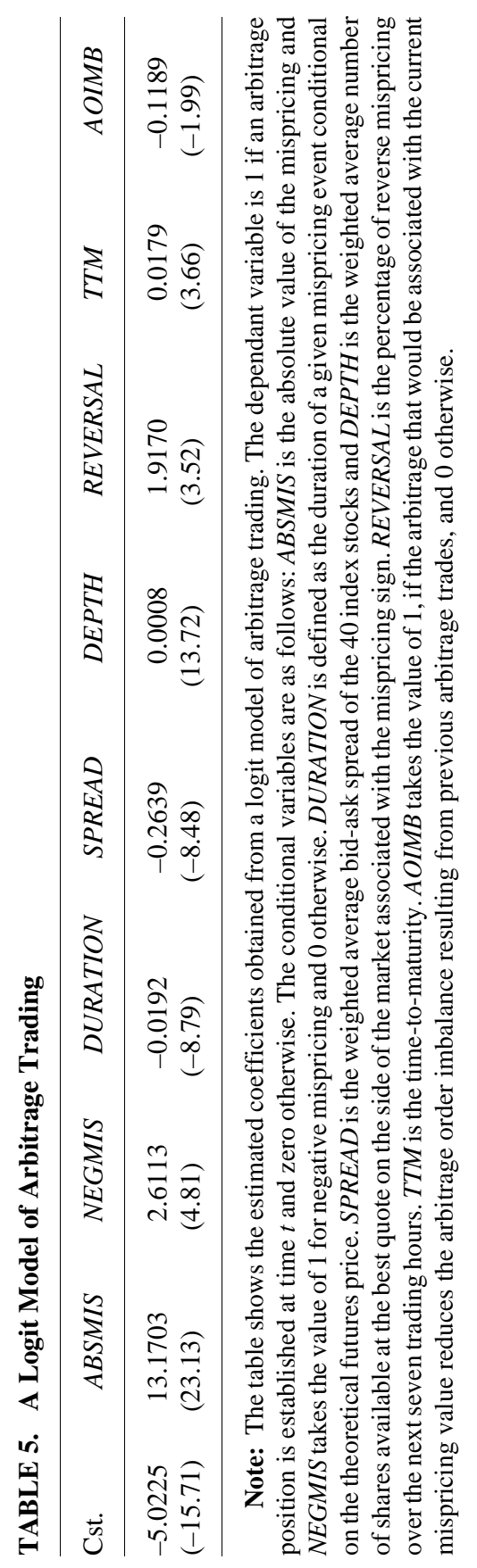




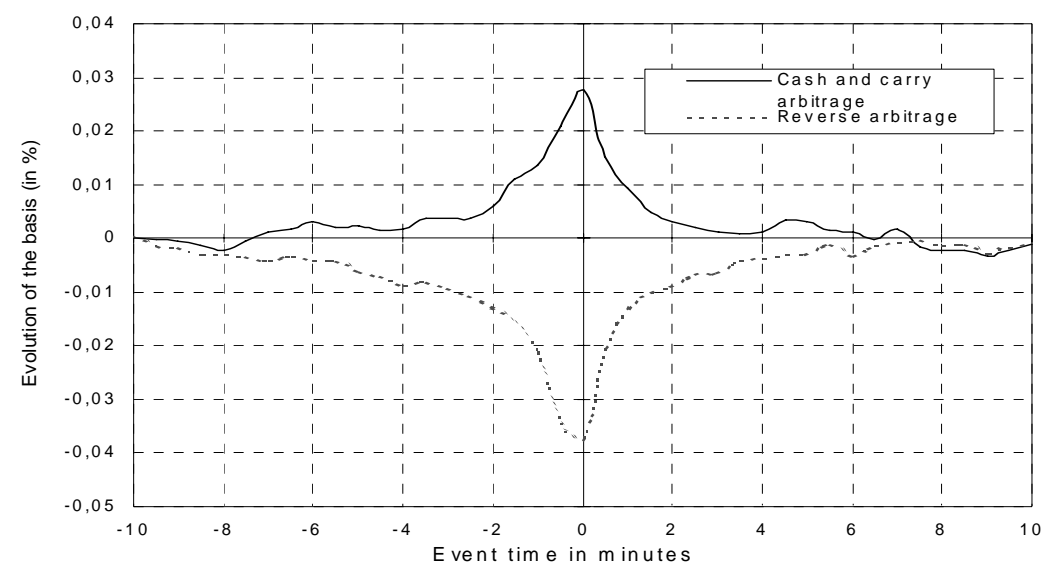

FIGURE 8.- Cumulative Basis Changes around Arbitrage Trading This figure displays the behavior of the basis surrounding buy and sell basket order submissions for the period from January 1995 through March 1995. The estimates plotted are obtained from time series regressions of the basis changes on leads and lags of buy and sell order submissions. This procedure is taken from Harris, Sofianos and Shapiro (1994) and allows us to account for the clustering effect observed in arbitrage order submissions.

sharply just one or two minutes before the order submission and then drops quickly after the arbitrage trade is completed. This provides direct evidence on the mean reversion induced by arbitrage trading and also indicates that the mispricing is not persistent around such events. It suggests that true arbitrage opportunities may be due to sudden price jumps induced by information arrivals that are quicky exploited by the arbitrageurs. This is consistent with models of informed arbitrage trading (e.g., Kumar and Seppi [1994]) and with the evidence that the futures price leads the index price around arbitrage trading. Figures 9 and 10 below present the plots of the cumulative changes in the index cash and futures value from 10 minutes before the trade to 10 minutes after the trade for cash and carry and reverse arbitrages.

The variables related to the option to liquidate the position early support the hypothesis that this option is of some value for arbitrageurs. The likelihood of establishing an arbitrage position is a positive 


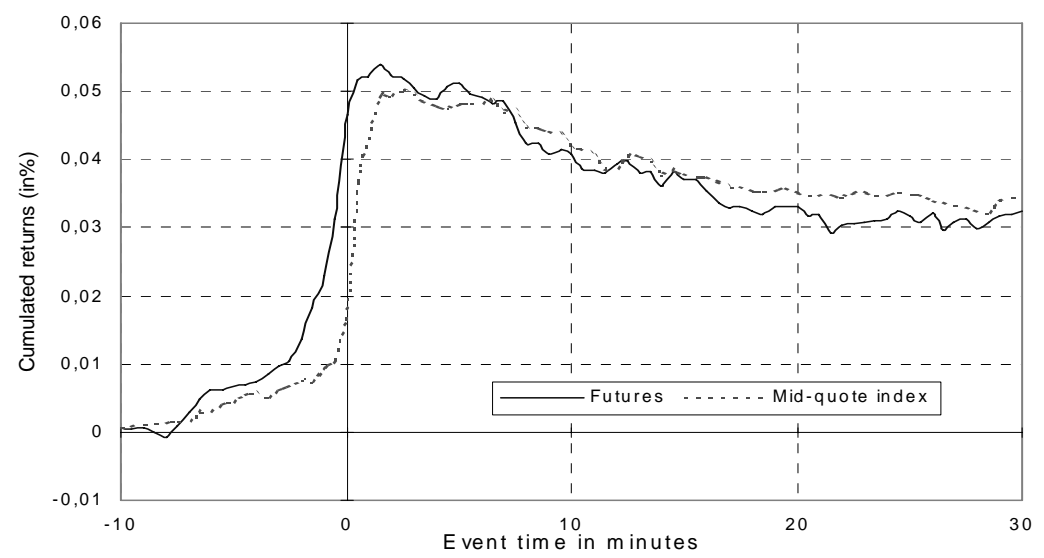

FIGURE 9.- The Price Impact of Cash and Carry Arbitrage This figure displays the cumulative returns of the mid-quote index and the cumulative price changes of the futures surrounding buy basket order submissions for the period from January 1995 through March 1995. The estimates plotted are obtained from time series regressions of the basis changes on leads and lags of buy and sell order submissions. This procedure is taken from Harris, Sofianos and Shapiro (1994) and allows us to account for the clustering effect observed in arbitrage order submissions.

function of the expected reversal in the basis indicating that arbitrageurs take into account the possibility to liquidate a position early when they are looking for arbitrage opportunities. The positive coefficient for the time to maturity is also consistent with arbitrageurs valuing the option to reverse their positions early. Curiously, arbitrage order imbalance has an impact on the likelihood of establishing a new arbitrage position opposite to the one we expected. Nevertheless the joint effect of a large number of data and a low critical value may indicate that arbitrage order imbalance has in fact no impact on the likelihood of establishing an arbitrage position. These results are consistent with the fact that arbitrageurs are forward-looking when establishing a position (as suggested by the coefficient of the REVERSAL variable), not backward-looking. 


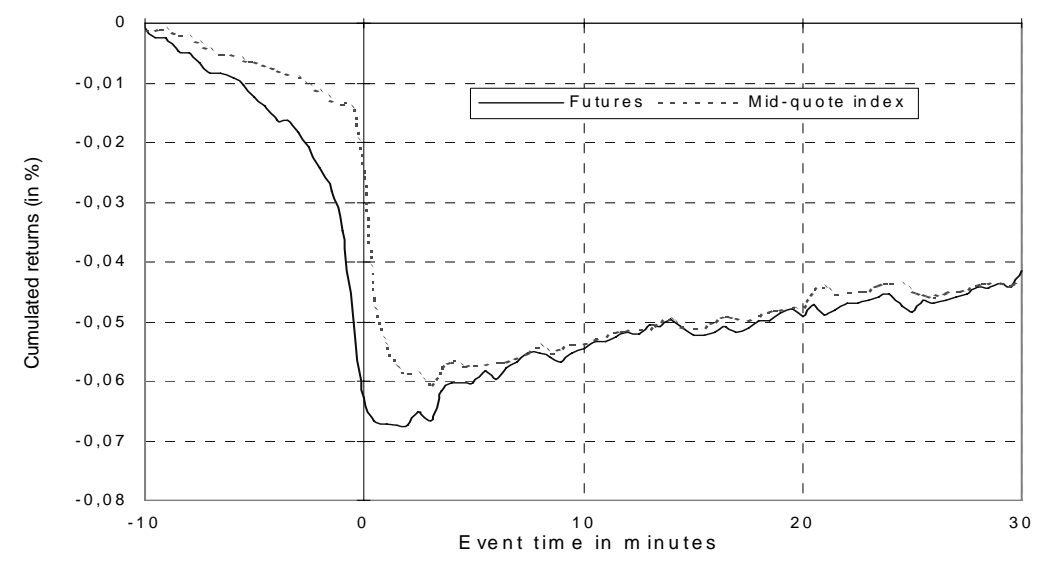

FIGURE 10.- The Price Impact of Reverse Cash and Carry Arbitrage This figure displays the cumulative returns of the mid-quote index and the cumulative price changes of the futures surrounding buy basket order submissions for the period from January 1995 through March 1995. The estimates plotted are obtained from time series regressions of the basis changes on leads and lags of buy and sell order submissions. This procedure is taken from Harris, Sofianos and Shapiro (1994) and allows us to account for the clustering effect observed in arbitrage order submissions.

Finally, while the model provides new results concerning the determinants of arbitrage trading, its ability to predict when an arbitrage position will be established is very low. The likelihood ratio index equals 0.088 and the $R$-squared from a similar $O L S$ regression equals 0.058. This is significantly better than the goodness of fit statistics reported in previous studies, a fact probably due to the new variables included in the model, but it is still very low. ${ }^{20}$ This suggests that while the liquidity of the market and the opportunity to reverse a position are important determinants in the arbitrage decision, a great deal of heterogeneity among arbitrageurs still remains. It also suggests that the actual mechanism of arbitrage trading may be far more complex than captured by the traditional threshold models. 


\section{Summary and Conclusions}

This paper focuses on the behavior of arbitrageurs in stock index cash and futures markets. Relying on a dataset of intra-day arbitrage orders in the French market, the persistence of mispricing and the arbitrage trading decision are analyzed.

Controlling for the statistical illusion induced by infrequent trading, we show that mispricing is not persistent because arbitrage opportunities are rapidly eliminated by stock index arbitrageurs but also because of some general mean reversion in mispricing changes.

We suggest that this result, which is reminiscent to the work by Miller, Muthuswamy and Whaley (1994), may be related to the fact that arbitrage trading is far less frequent and predictable that it would be found by applying some mechanical trading rules based on the mispricing value.

We suggest that the non-arbitrage mean reversion may be related to the behavior of limit order traders facing liquidity shocks and also to stale quotes in the cash market. The first explanation is consistent with evidence of limit order traders over-bidding/undercutting on large spreads and also with the low level of depth out of the best quotes (e.g. Biais, Hillion and Spatt [1995]). The second explanation may be related to lead-lag relationships between the futures and the stocks and is also consistent with the partial adjustment model of Theobald and Yallup (2001).

In this context, the behavior of arbitrageurs appears highly competitive. The results are consistent with what one would expect theoretically if arbitrageurs were $100 \%$ certain being able to unwind their position prior to the maturity date and competition among arbitrageurs had eliminated all excess rents. That is, we find that on average the net arbitrage profit is at the competitive level of zero. Finally we show that the depth of the market affect significantly arbitrage trading.

Additional research is needed to increase our ability to predict when an arbitrage position is established. Future work may examine the extent to which arbitrageurs act as an homogeneous set of investors using actual arbitrage data. In the same vein, the aggressiveness of arbitrage trading may be analyzed. 


\section{References}

Biais, B.; Hillion, P.; and Spatt, C. 1995. An empirical analysis of the limit order book in the Paris Bourse. Journal of Finance 50 (December): 1655-1689.

Brennan, M., and Schwartz, E. 1990. Arbitrage in stock index futures. Journal of Business 3 (January): S7-S31.

Chan, K. 1993. Imperfect information and cross-autocorrelation among stock prices. Journal of Finance 48 (September): 1211-1230.

Cheung, Y.-W., and Fung, H.-G. 1997. Information flows between Eurodollar spot and futures markets. Multinational Journal of Finance 1 (December): 255-271.

Chung, Y.P. 1991. A transaction data test of stock index futures market efficiency and index arbitrage efficiency. Journal of Finance 46 (December): 1791-1809.

Dwyer, G.P. Jr; Locke P.; and Yu W. 1996. Index arbitrage and nonlinear dynamics between the S\&P 500 futures and cash. Review of Financial Studies 9 (Spring): 301-332.

Fremault, A. 1991. Index futures and index arbitrage in a rational expectation model. Journal of Business 64 (October): 523-548.

Froot, K.A., and Pérold A.F. 1995. New trading practices and short-run market efficiency. Journal of Futures Markets 15 (October): 731-765.

Harris, L.; Sofianos, G.; and Shapiro J.E. 1994. Program trading and intraday volatility. Review of Financial Studies 7 (Winter): 653-685.

Holden, C.W. 1995. Index arbitrage as cross-sectional market making. Journal of Futures Markets 15 (June): 423-455.

Holden, C.W. 1990. Intertemporal arbitrage trading : theory and empirical tests. Working Paper. Indiana University.

Kawaller, I.G. 1991. Determining the relevant fair value(s) of the S\&P 500 futures: A case study approach. Journal of Futures Markets 11 (August): 423-455.

Kempf, A. 1998. Short selling, unwinding, and mispricing. Journal of Futures Market 18 (December): 903-923.

Kraus, A., and Stoll, H.R. 1972. Price impacts of block trading on the New York Stock Exchange. Journal of Finance 27 (June): 569-588.

Kumar, P., and Seppi, D. 1994. Information and index arbitrage. Journal of Business 67 (October): 481-509.

Lambrecht, B. 2000. The timing of arbitrage: An options approach. Finance 21 (December):131-167.

Lim, K.-G. 1992. Arbitrage and price behavior of Nikkei stock index futures. Journal of Futures Markets 12 (April): 151-161.

MacKinlay, A.C., and Ramaswamy, K. 1988. Index-futures arbitrage and the behavior of stock index futures prices. Review of Financial Studies 1 (Summer): 137-158. 
McDonald, R.L. 2001. Cross-border investing with tax arbitrage : The case of German tax credits. Review of Financial Studies 14 (Fall): 617-657.

Miller, M.H.; Muthuswamy, J.; and Whaley, R.E. 1994. Mean reversion of S\&P 500 index basis changes: Arbitrage induced or statistical illusion? Journal of Finance 49 (June): 479-513.

Neal, R. 1996. Direct tests of index arbitrage models. Journal of Financial and Quantitative Analysis 31 (December): 541-562.

Sofianos, G. 1993. Index arbitrage profitability. Journal of Derivatives 1 (Fall): 6-20.

Spatt, C.S., and Sterbenz, F.P. 1985. Learning, preemption and the degree of rivalty. Rand Journal of Economics 16 (Spring): 84-92.

Stoll, H.R., and Whaley, R.E. 1990. The dynamics of stock index and stock index futures returns. Journal of Financial and Quantitative Analysis 25 (December): 441-468.

Strickland, C., and Xu, X. 1993. Behavior of the FTSE-100 basis. Review of Futures Markets 12 (September): 459-502.

Theobald, M., and Yallup, P. 2001. Mean reversion and basis dynamics. Journal of Futures Markets 21 (September): 797-818.

Theobald, M., and Yallup, P. 1996. Settlement, tax and non-synchronous effects in the basis of UK stock index futures. Journal of Banking and Finance 20 (November): 1509-1530.

Tse, Y. 2001. Index arbitrage with heterogeneous investors: A smooth transition error correction model. Journal of Banking and Finance 25 (October): $1829-1855$.

Venkataraman, K. (2001). Automated versus floor trading: An analysis of execution costs on the Paris and New York exchanges. Journal of Finance 56 (August) 1445-1485.

Yadav, P.K., and Pope, P.F. 1994. Stock index futures mispricing: Profit opportunities or risk premia. Journal of Banking and Finance 18 (October): 921-953.

Yadav, P.K., and Pope, P.F. 1990. Stock index futures pricing: International evidence. Journal of Futures Markets 10 (December): 573-603. 